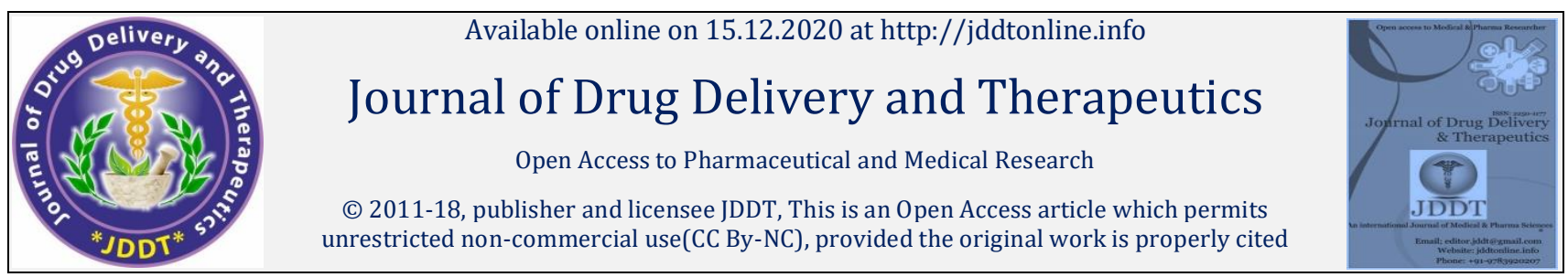

Open $\odot$ Access

Review Article

\title{
Solid lipid nanocarriers as alternative drug delivery system for improved oral delivery of drugs
}

\author{
Thirupathi Gorre*, Kumara Swamy Samanthula, Ramesh Alli \\ Department of Pharmaceutics, Vaagdevi Pharmacy College, Bollikunta, Warangal, Telangana State, India \\ $¥$ All authors contributed equal to this work
}

\begin{abstract}
Oral bioavailability of drugs is mainly limited due to the poor aqueous solubility, enhanced chemical degradation, reduced permeation and/or first pass metabolism. Various novel delivery systems are developed for improved oral bioavailability of these drugs such as modified orals, buccal, transdermal and osmotic delivery systems. Colloidal carrier systems such as nanoparticles, lipid nanoparticles, nanoe mulsions, microspheres, liposomes, resealed erythrocytes and transfersomes were also developed to enhance the oral delivery. Among these, solid lipid nanocarriers (SLNs) also gain much attention on the enhancement of oral bioavailability. SLNs are submicron sized nanoparticles and composed of solid lipid, surfactants and cosurfactants. The enhanced oral bioavailability of poorly soluble drugs from SLNs might be due to the reduced particle size, bypassed presystemic metabolism, and enhanced gastric mucosa permeability. Vast literature is available for the advantages, limitations, preparation methods, evaluation parameters and application of SLNs in different routes. This review mainly focused on list of drugs developed as SLNs and considered as an alternative approach to enhance the oral bioavailability based on pharma cokinetic as well as pharmacodyanmic parameters was discussed.
\end{abstract}

Keywords: Oral bioavailability, solubility, first-pass metabolism, solid lipid nanoparticles, pharmacokinetics, pharmacodynamics.

\section{Article Info: Received 09 Oct 2020; $\quad$ Review Completed 17 Nov 2020; $\quad$ Accepted 23 Nov 2020; Available online 15 Dec 2020}

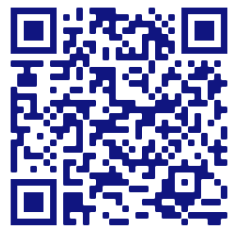

Cite this article as:

Thirupathi G, Kumara Swamy S, Ramesh A, Solid lipid nanocarriers as alternative drug delivery system for improved oral delivery of drugs, Journal of Drug Delivery and Therapeutics. 2020; 10(6-s):168-172 http://dx.doi.org/10.22270/jddt.v10i6-s.4410

*Address for Correspondence:

Thirupathi Gorre, Department of Pharmaceutics, Vaagdevi Pharmacy College, Bollikunta, Warangal, Telangana State, India

\section{INTRODUCTION}

Different Drug Delivery Systems have been generally developed to improve the bioavailability of ineffectively assimilated drugs with a specific objective to enhance their clinical efficiency when administered orally. It is evaluated that in about $40-70 \%$ of all new drugs are developed as poor solubility in aqueous environment ${ }^{1}$. The expansion in the extent of ineffectively dissolvable competitors is every now and again credited to upgrades in combination innovation, which has empowered the outline of extremely confounded mixes, and an adjustment in revelation system from a supposed phenotypic way to deal with an objective based approach ${ }^{2}$. Different physicochemical properties which add to the poor dissolvability of different drugs incorporate their perplexing structure, estimate, high molecular weight, high lipophilicity, compound $\mathrm{H}$-attaching to dissolvable, intramolecular $\mathrm{H}$-holding, intermolecular $\mathrm{H}$ holding (precious stone pressing), crystallinity, polymorphic structures, ionic charge status, $\mathrm{pH}$, and salt shape $\mathrm{e}^{3,4}$.
Various approaches have been used to enhance the oral bioavailability of poorly soluble drugs. These approaches includes; i) enhance the solubility and dissolution rate using liquisolid compacts (Arun and Narendar, 2016), solid dispersion by complexation ${ }^{5-7}$, ii) by avoiding the presystemic metabolism using buccal delivery ${ }^{8-10}$, semi solid dispersions ${ }^{11}$, iii) prolong the drug release using floating delivery $12-15$, sustained delivery and osmotic delivery 16,17 , multiunit dosage form ${ }^{18-20}$; chrono and colon delivery ${ }^{21,} 22$; iv) reducing the particle size by using micronization and nanonization such as self-emulsifying delivery ${ }^{23}$, solid lipid nanoparticles ${ }^{24}$, cubosmes ${ }^{25}$, nanosuspension ${ }^{26}$, transfersomes and ethosomes ${ }^{27-29}$, nanocrystals ${ }^{30}$, nanoemulsion ${ }^{31,32}$ and microemulsions ${ }^{33}$; Among various approaches, lipid nanocarriers (solid lipid nanoparticles (SLNs) and nanostructured lipid carriers (NLCs)) considered to be as vehicle for one of the novel delivery system for improvement of oral bioavailability34,35). A vast variety of literatur available on enhanced oral delivery in terms of pharmacokinetic and pharmacodynamic activity of poorly soluble drugs reported 36,37 . 
SLNs are defined as a sub-micron colloidal carrier with particle size between $50-1000 \mathrm{~nm}^{38}$, 39. SLNs have the advantages over other colloidal carrier systems especially compared with polymeric nanoparticles, nanoemulsions and nanostructured lipid carriers 40,41 . Compared with other systems, SLNs has many benefits including ease of preparation, low cost, high-scale production, excellent physical stability, good release profile, chemical versatility, preparation in the absence of organic solvent, no toxicity of lipid carrier system, biodegradability of lipids, being cheaper than polymeric carrier, being easier to get approval and reliability and biodegradability of lipids ${ }^{42,43}$. In general, SLNs are made of combination of solid lipids which are solid at room temperature, surfactants and co-surfactants $44-46$.

SLNs enhance the bioavailability, sustained drug release, tumor targeting, surface modification and loading of both hydrophilic and liphophilic drugs ${ }^{47-49}$. SLNs have the additional advantage of reduced cytotoxicity, improved ocular delivery and enhanced pharmacodynamic activity50, 51. Previously, Meharant and Mader, 52 reported the systemic review on production methods and secondary steps for stabilization; Uner and Yaner, reported the application of SLNs in different routes and ocular delivery53-55; Jenning et al., discussed various evaluation methods ${ }^{56}$; effect of SLNs in dermal applications as cosmetics 57,58 and used as vehicle for bioactive compounds reported 59 . In this review mainly focus on the role of solid lipid nanoparticles to improve the oral bioavailability of poorly soluble drugs based on pharmacokinetic and pharmacodynamic parameters.

\section{CASE STUDIES OF DRUG LOADED SOLID LIPID NANOPARTICLES}

Müller et al., 60 formulated and reported the enhanced oral bioavailability of cyclosporine form SLN formulation compared with nanocrystals and marketed microemulsion Sandman Neoral/Optoral ${ }^{\circledR}$ formulation as reference formulation. The AUC values $>1000$ and $>12,000 \mathrm{ng} / \mathrm{ml}$ being 0.4 and $0.0 \%$ of the total AUC for SLN, but 6.5 and $2.9 \%$ in case of the microemulsion. Müller et al., 61 developed and reported the in vitro characterization of cyclosporine loaded SLNs using Imwitor 900 as lipid matrice. From the results, cyclosporine loaded SLNs exhibited more inclusion of cyclosporine and also more drug release. Based on wide angle X-ray scattering studies, cyclosporine is molecularly dispersed in between the fatty acid chains of the liquidcrystalline alpha-modification fraction of the loaded SLN.

Lopinavir (LP) loaded SLNs were used to enhance the lymphatic uptake of LA by overcoming the lymphatic transport. LP-SLNs were prepared by glyceryl behenate using hot homogenization coupled with probe sonication method. The particle size, PDI and zeta potential of optimized SLNs was found to be $230 \mathrm{~nm}, 0.27$ and $-27 \mathrm{mV}$, respectively. About 4.91-fold enhancement in the lymphatic uptake was observed with in vitro cumulative studies in $0.1 \mathrm{~N} \mathrm{HCl}$ followed by $\mathrm{pH} 6.8$ phosphate buffer. In vivo studies in male albino rats showed 2.13-fold improvement when compared with LP suspension, as control formulation ${ }^{62}$.

Statistically optimized nisoldipine loaded solid lipid nanoparticles (ND-SLNs) were developed using central composite design to improve oral bioavailability. ND-SLNs were prepared by homogenization followed by ultra sonication method using Dynasan-114 as lipid matric, egg lecithin as surfactant and poloxamer 188 as co-surfactant. Particle size, PDI, zeta potential and entrapment efficiency of ND-SLN was found to be $104.4 \pm 2.13 \mathrm{~nm}$, PDI of $0.241 \pm 0.02$ and EE of $89.84 \pm 0.52 \%$ respectively. Further N-SLN showed sustained release for upto $24 \mathrm{~h}$. The pharmacokinetic study revealed the about 2.35-fold enhancement in oral bioavailability and $36 \mathrm{~h}$ prolonged pharmacodynamic effect when compared with ND suspension in Albino Wistar rats63.

Oral bioavailability of olmesartan medoxomil (OM) was improved by solid lipid nanoparticles delivery system. Nooli et al., ${ }^{64}$ reported the enhanced oral BA of OM 2.32-times more in male Sprague Dawley rats compared with OM plain drug solution. Similarly, Arun et al., 2018, reported the about 7.21-folds improvement and 3.52-folds improvement compared with OM coarse suspension and nanosuspension formulation, respectively65. Recently, Pandya et al., 2018, developed the SLNs of OM to increase the oral BA by employing central composite design. From his findings, about 2.3-fold enhancement in the OM-SLNs were reported compared with marketed formulation 66 .

Similarly, candesartan cilexetil, angiotensin receptor 1 antagonist, prescribed for the treatment of hypertension. The bioavailability of candesartan cilexetil was less than $20 \%$ owing to poor solubility and pre-systemic metabolism. Therefore, an attempt was made to enhancement in the bioavailability using SLNs delivery system. SLNs of CC were prepared by using triglycerides as solid lipid matrices. The BA of CC loaded SLNs were increased by more than 2.85folds compared with coarse CC suspension formulation in albino Wistar rats at a dose of $10 \mathrm{mg} / \mathrm{kg}^{67}$. Zhang et al., also reported the improvement in oral bioavailability of candesartan was 12 -folds more after incorporation into solid lipid nanoparticles ${ }^{68}$.

Felodipine is an antihypertensive drug with poor oral bioavailability due to the first pass metabolism. Solid lipid nanoparticles as considered as alternative delivery system to improve the BA. Therefore, felodipine loaded solid lipid nanoparticles (SLNs) were developed using triglycerides as lipid matrices and prepared by hot homogenization followed by sonication method. Pharmacokinetics of felodipine-SLNs after oral administration in male Wistar rats was studied. The BA of felodipine loaded SLNs was increased by 1.75folds when compared to that of a felodipine coarse suspension 69 .

Lacidipine (LD) loaded solid lipid nanoparticles (LD-SLNs) were reported by Sandeep et al., 6 for improving the oral bioavailability. LD-SLNs were prepared in two steps. First step was hot homogenization-ultrasonication method, using triglycerides (tripalmitin and tristearin), monoglyceride and surfactants (Poloxamer 188 and egg lecithin E80). LD-SLNs prepared with Dynasan-116 (F3) having the size of $141.86 \mathrm{~nm}$, PDI of 0.293 , P of $-22.3 \mathrm{~m}$ with $94.75 \%$ of EE was optimized and was stable for 60 days. Further, pharmacokinetic studies were conducted in Wistar rats. The relative bioavailability of LD in SLNs was 2.03-times when compared with that of the LD suspension. The results are indicative of SLNs as suitable lipid based carrier system for improving the oral bioavailability of $\mathrm{LD}^{70}$.

Rosuvastatin calcium (RC) is a hypolipidemic drug with poor oral bioavailability due to poor aqueous solubility and firstpass metabolism. Solid lipid nanoparticles are used to improve the oral bioavailability of RC. RC-SLNs were prepared by triglycerides using homogenization method The SLNs showed sustained delivery of RC upto $24 \mathrm{~h}$. In vivo studies revealed the 2 -folds enhancement in oral bioavailability compare with suspension formulation in rats ${ }^{49}$. Further, attempts were made to improve the oral bioavailability of RC using monoglycerides to reduce the cost of manufacturing and processing. RC-SLNs were developed using Dynasan-112, glyceryl monostearate and stearic acid RC-SLNs prepared with Dynasan-112 showed below $100 \mathrm{~nm}$ 
size with less than $0.3 \mathrm{PDI}$ and $-26 \mathrm{mV}$ zeta potential. RCSLNs showed more than $80 \%$ drug release in $24 \mathrm{~h}$ from dialysis method using $0.1 \mathrm{~N} \mathrm{HCl}$ followed by $\mathrm{pH} 6.8$ phosphate buffer as release media. DSC and XRD studies confirmed the conversion of crystalline to amorphous state. TEM and SEM analyze the particle shape and were found to be nearly spherical in shape with increased polydispersity. The enhancement on the oral bioavailability from SLN was found to be 4.5-folds compared with suspension formulation in male albino rats. Further, pharmacodynamic studies exhibited reduced total cholesterol, LDL, VLDL and enhanced HDL levels for $36 \mathrm{~h}$ compared with suspension formulation ${ }^{71}$.

Simvastatin loaded solid lipid nanoparticles were prepared to improve the oral bioavailability. Glyceryl behenate and glyceryl palmitostearate used as solid lipids containing Tween 80 as surfactant. Entrapment efficiency and size of the particles were more than $96 \%$ and below $200 \mathrm{~nm}$ respectively. The electron micrographs indicated that lipid nanocarriers were almost spherical in appearance. X-ray diffraction and differential calorimetric studies proved that the drug was amorphous form in the lipid matrix Pharmacodynamic studies of simvastatin solid lipid nanoparticles exposed superior reduction in total cholesterol values as compared to pure drug powder indicating enhanced oral bioavailability of Simvastatin 72 .

Sorafenib is poorly water-soluble drug with low oral bioavailability and reduced liver targeting property. SLNs were developed to enhance the oral bioavailability as well as liver targeting of sorafenib (SR-SLNs) ${ }^{73}$. The EE and DL of SR-SLNs were 89.87 and $5.39 \%$ respectively. Particle size, PDI, and zeta potential of SR-SLNs were $77.16 \mathrm{~nm}, 0.28$, and $-18.1 \mathrm{mV}$, respectively. The liver-targeting and oral bioavailability results showed that the average drug selectivity index value of SR-SLNs was 2.20-times and $66.7 \%$ more than that of the SR-suspension formulation respectively, after oral administration to male Wistar rats (7.5 mg/kg).

Altretamine-loaded solid lipid nanoparticle (AL-SLNs) was developed by using Box-Behnken design to improve the oral absorption. The SLNs were evaluated for mean particle size, entrapment efficiency, and drug-loading. The optimized formulation, with a desirability factor of 0.92 , was selected and characterized. In vitro release studies showed a biphasic release pattern from the SLNs for up to $24 \mathrm{~h}$. The results of $\%$ EE $(93.21 \pm 1.5)$, \%DL $(1.15 \pm 0.6)$, and mean diameter of $(100.6 \pm 2.1) \mathrm{nm}$, were very close to the predicted values ${ }^{74}$.

Narendar and Karthik, developed the solid lipid nanoaprticles of zalpeplon to improve the oral bioavailability using response surface methodology 75 . The prepared ZL-SLNs were spherical in shape with increased PDI after lyophilization. ZL was converted to amorphous form when loaded in SLNs, which was confirmed by DSC and XRD studies. Drug release was continued for more than $24 \mathrm{~h}$ through dialysis method. In vivo studies after oral administration of SLNs showed around 2.5-folds improvement in bioavailability compared with pure drug coarse suspension in rats.

Madhu et al., developed the lyophilized raloxifene hydrochloride (RH) solid lipid nanoparticles to improve the oral bioavailability due to its poor bioavailability76. RH-SLNs were prepared using triglecrides as solid lipids and characterized for optimized system based on particle size, entrapment efficiency and zeta potential Further, converted to powder form by subjecting to freeze drying. RH loaded into converted to amorphous form confirmed by DSC and XRD studies. In situ intestine perfusion studies exhibited more drug permeation in GIT of rat. In vivo pharmacokinetic study evidenced for improved oral bioavailability of RH from SLNs, after oral administration to rats and compared with suspension as control.

\section{CONCLUSIONS AND FUTURE PERSPECTIVES}

Poor bioavailability of drugs is a major limitation in successful drug delivery by oral route of administration. Abundant research developments are in progressive, especially with novel delivery approaches and nano carriers is focused on enhancement of oral bioavailability of poorly absorbed drugs. Further, it is important to understand the purpose for the poor bioavailability before outlining delivery systems. The positive outcomes got with the utilization of different delivery systems or diverse methodologies of bioavailability improvement appear to guarantee. Accordingly, the commercial improvement of the SLN delivery systems significantly requires more research for overcome the difficulties; for example, scale up, cost viability and unsteadiness of a portion of the details. Various methods have been developed with a focus on enhancement of the scale up and manufacturing errors limitations. To complete development works within a limited amount of time, the establishment of a SLN strategy should be one of the best approach for the pharmaceutical development of poorly water-soluble drugs.

\section{REFERENCES}

1. Savjani KT, Gajjar AK, Savjani JK. Drug solubility: importance and enhancement techniques. ISRN pharmaceutics. 2012; 2012.

2. Blagden N, de Matas M, Gavan PT, York P. Crystal engineering of active pharmaceutical ingredients to improve solubility and dissolution rates. Advanced Drug Delivery Reviews. 2007; 59(7):617-630.

3. Shefter E, Higuchi T. Dissolution behavior of crystalline solvated and nonsolvated forms of some pharmaceuticals. Journal of Pharmaceutical Sciences. 1963; 52:781-791.

4. Patil SV, Sahoo SK. Pharmaceutical overview of spherical crystallization. Der Pharmacia Lettre. 2010; 2(1):421-426.

5. Arun B, Narendar D. Enhancement of solubility and dissolution rate of trandolapril sustained release matrix tablets by liquisolid compact approach. Asian Journal of Pharmaceutics. 2015; 9(4):290-297.

6. Swetha E, Narendar D. Influence of $\beta$-cyclodextrin and hydroxypropyl- $\beta$-cyclodextrin on enhancement of solubility and dissolution of isradipine. International Journal of Pharmaceutical Sciences and Nanotechnology. 2017; 10(3):3752-3757.

7. Palem Chinna Reddy, Narendar D, Satyanarayana Goda and Varsha B Pokharkar. Development and optimization of atorvastatin calcium-cyclodextrin inclusion complexed oral disintegrating tablets for enhancement of solubility, dissolution, pharmacokinetic and pharmacodynamic activity by central composite design. International Journal of Pharmaceutical Sciences and Nanotechnology. 2016; 9(2):1-11.

8. Chinna Reddy P, Ramesh G, Narender D, Vamshi Vishnu Y, Madhusudan Rao Y. Transmucosal delivery of domperidone from bilayered buccal patches: in vitro, ex vivo and in vivo characterization. Archives of Pharmacal Research. 2011; 34(10):1701-1710.

9. Palem CR, Dudhipala NR, Battu SK, Repka MA, Rao Yamsani M. Development, optimization and in vivo characterization of domperidone-controlled release hot-melt-extruded films for buccal delivery. Drug development and industrial pharmacy. 2016 Mar 3; 42(3):473-84.

10. Palem CR, Dudhipala N, Battu SK, Goda S, Repka MA, Yamsani MR. Combined dosage form of pioglitazone and felodipine as mucoadhesive pellets via hot melt extrusion for improved buccal delivery with application of quality by design approach. Journal of Drug Delivery Science and Technology. 2015; 30:20919.

11. Narendar D, Arjun N, Dinesh S, Karthik J. Biopharmaceutical and preclinical studies of efficient oral delivery of zaleplon as semisolid dispersions with self-emulsifying lipid surfactants. 
International Journal of Pharmaceutical Sciences and Nanotechnology. 2016; 9(1):1-8.

12. Doodipala NR, Sunil R, Rao M. Development of floating matrix tablets of Ofloxacin and Ornidazole in combined dosage form: in vitro and in vivo evaluation in healthy human volunteers. International Journal of Drug Delivery. 2012; 4(4):462.

13. Narendar D, Arjun N, Someshwar K, Rao YM. Quality by design approach for development and optimization of Quetiapine Fumarate effervescent floating matrix tablets for improved oral bioavailability. Journal of Pharmaceutical Investigation. 2016 Jun 1; 46(3):253-63.

14. Donthi MR, Dudhipala NR, Komalla DR, Suram D, Banala N. Preparation and Evaluation of Fixed Combination of Ketoprofen Enteric Coated and Famotidine Floating Mini Tablets by Single Unit Encapsulation System. Journal of Bioequivalence \& Bioavailability. 2015; 7(6):279.

15. Narendar D, C.R. Palem, S. Reddy and Y. M. Rao. Pharmaceutical development and clinical pharmacokinetic evaluation of gastroretentive floating matrix tablets of levofloxacin. International Journal of Pharmaceutical Sciences and Nanotechnology. 2011; 4(3):1461-1467.

16. Nagaraj B. Development of osmotically controlled oral drug delivery systems of tramadol hydrochloride: effect of formulation variables on in vitro release kinetics. Asian Journal of Pharmaceutics. 2016; 10(03).

17. Arjun N, Narendar D, Sunitha K, Harika K, Nagaraj B. Development, evaluation, and influence of formulation and process variables on in vitro performance of oral elementary osmotic device of atenolol. International journal of pharmaceutical investigation. 2016; 6(4):238.

18. Mahipalreddy D, Narendar D, Devendhar K, Dinesh S, Kiran S, Nagaraj B. Preparation and evaluation of ketoprofen enteric coated mini tablets for prevention of chronic inflammatory disease. J Pharm Drug Deliv Res. 2015; 4(2).

19. Arun B. Reddy and Narendar D. Development of multiple-unit floating drug delivery system of clarithromycin: formulation, in vitro dissolution by modified dissolution apparatus, in vivo radiographic studies in human volunteers. Drug research. 2017; 67:412-418

20. Donthi MR, Dudipala N, Komalla DR, Suram D, Banala N. Design and Evaluation of Floating Multi Unit Mini Tablets (MUMTS) Muco Adhesive Drug Delivery System of Famotidine to Treat Upper Gastro Intestinal Ulcers. Journal of Pharmacovigilance. 2015 Oct 12.

21. Alekya T, Narendar D, Mahipal D, Arjun N, Nagaraj B. Design and evaluation of chronomodulated drug delivery of tramadol hydrochloride. Drug research. 2018; 68(03):174-80.

22. Rajitha R, Narendar D, Arjun N, Nagaraj B. Colon delivery of Naproxen: Preparation, Characterization and Clinical evaluation in healthy volunteers. International Journal of Pharmaceutical Sciences and Nanotechnology. 2016; 9(4):3383-9.

23. Krishna VM, Kumar VB, Dudhipala N. In-situ Intestinal Absorption and Pharmacokinetic Investigations of Carvedilol Loaded Supersaturated Self-emulsifying Drug System. Pharmaceutical nanotechnology. 2020 Jun 1; 8(3):207-24.

24. Narendar D and Kishan V. Candesartan cilexetil nanoparticles for improved oral bioavailability. Therapeutic delivery. 2017; 8(2):79-88.

25. Arun B, Arjun. $\mathrm{N}$ and Narendar D. Formulation and characterization of Liquid Crystalline Hydrogel of Agomelatin: In vitro and Ex vivo evaluation. Journal of applied Pharmaceutical Science. 2015; 5(9):110-114.

26. Nagaraj K, Narendar D, Kishan V. Development of olmesartan medoxomil optimized nanosuspension using the Box-Behnken design to improve oral bioavailability. Drug Development and Industrial Pharmacy. 2017 Jul 3; 43(7):1186-96.

27. Pitta SK, Dudhipala N, Narala A, Veerabrahma K. Development of zolmitriptan transfersomes by Box-Behnken design for nasal delivery: in vitro and in vivo evaluation. Drug development and industrial pharmacy. 2018 Mar 4; 44(3):484-92.

28. Narendar D, Riyaz PMD, Ahmed AY, Nagaraj B. Effect of lipid and edge activator concentration on development of Aceclofenac loaded transfersomes gel for transdermal application: in vitro and ex vivo skin permeation. Drug development and industrial pharmacy. 2020; 46(8):1334-1344.

29. Shruthi K, Narendar D, Arjun N, Kishan V. Development and Antimicrobial Evaluation of Binary Ethosomal Topical Gel of Terbinafine Hydrochloride for the Treatment of Onychomycosis.
International Journal of Pharmaceutical Sciences and Nanotechnology. 2018; 11:3998-4005.

30. Karri V, Arun B, Narender D. Fabrication of efavirenz freeze dried nanocrystals: formulation, physicochemical characterization, in vitro and ex vivo evaluation. Advanced Science, Engineering and Medicine. 2015; 7(5):385-392.

31. Reddy KR, Reddy DN, Botla S, Reddy PG. Development, Characterization and In Vivo Performance of Saquinavir Loaded Lipid Microspheres. Advanced Science, Engineering and Medicine. 2015 Nov 1; 7(11):944-51.

32. Sweeney C, Dudhipala N, Thakkar R, Mehraj T, Marathe S, Gul W, ElSohly MA, Murphy B, Majumdar S. Effect of surfactant concentration and sterilization process on intraocular pressurelowering activity of $\Delta$ 9-tetrahydrocannabinol-valinehemisuccinate (NB1111) nanoemulsions. Drug delivery and translational research. 2020; 9:1-2.

33. Nagaraj B, Anusha K, Narendar D, Sushma P. Formulation and evaluation of microemulsion-based transdermal delivery of duloxetine hydrochloride. International Journal of Pharmaceutical Sciences and Nanotechnology. 2020; 13(1):4773-82.

34. Tirumalesh C, Suram D, Dudhipala N, Banala N. Enhanced pharmacokinetic activity of Zotepine via nanostructured lipid carrier system in Wistar rats for oral application. Pharmaceutical Nanotechnology. 2020 Apr 1; 8(2):148-60.

35. Nagaraj B, Tirumalesh C, Dinesh S, Narendar D. Zotepine loaded lipid nanoparticles for oral delivery: development, characterization, and in vivo pharmacokinetic studies. Future Journal of Pharmaceutical Sciences. 2020 Dec; 6(1):1-1.

36. Dudhipala N. A Comprehensive review on solid lipid nanoparticles as delivery vehicle for enhanced pharmacokinetic and pharmacodynamic activity of poorly soluble drugs. International Journal of Pharmaceutical Sciences and Nanotechnology. 2019; 12:4421-40.

37. Dudhipala N. Influence of solid lipid nanoparticles on pharmacodynamic activity of poorly oral bioavailable drugs. international Journal of Pharmaceutical Sciences and Nanotechnology. 2020; 13(4):4979-4983.

38. Mehnert W, Mader K. Solid lipid nanoparticles: Production, characterization and applications. Advanced Drug Delivery Reviews. 2001;47(2-3):165-96.

39. Schwarz C. Solid lipid nanoparticles (SLN) for controlled drug delivery II. Drug incorporation and physicochemical characterization. Journal of microencapsulation. 1999 Jan 1; 16(2):205-13.

40. Müller RH, Radtke M, Wissing SA. Solid lipid nanoparticles (SLN) and nanostructured lipid carriers (NLC) in cosmetic and dermatological preparations. Advanced Drug Delivery Reviews. 2002; 54:S131-55.

41. Dudhipala N, Janga KY, Gorre T. Comparative study of nisoldipine-loaded nanostructured lipid carriers and solid lipid nanoparticles for oral delivery: preparation, characterization, permeation and pharmacokinetic evaluation. Artificial cells, nanomedicine, and biotechnology. 2018 Nov 5; 46(sup2):61625.

42. Pardeshi C, Rajput P, Belgamwar V, Tekade A, Patil G, Chaudhary K, Sonje A. Solid lipid based nanocarriers: an overview. Acta Pharmaceutica. 2012 Dec 31; 62(4):433-72.

43. Narendar D, Thirupathi G. Neuroprotective effect of ropinirole loaded lipid nanoparticles hydrogel for Parkinson's disease: preparation, in vitro, ex vivo, pharmacokinetic and pharmacodynamic evaluation. Pharmaceutics. 2020, 12(5):448.

44. Das S, Chaudhury A. Recent advances in lipid nanoparticle formulations with solid matrix for oral drug delivery. AAPS PharmSciTech. 2011; 12(1):62-76.

45. Naseri N, Valizadeh H, Zakeri-Milani P. Solid lipid nanoparticles and nanostructured lipid carriers: structure, preparation and application. Advanced pharmaceutical bulletin. 2015 Sep; 5(3):305.

46. Dudhipala N, Ay AA. Amelioration of ketoconazole in lipid nanoparticles for enhanced antifungal activity and bioavailability through oral administration for management of fungal infections. Chemistry and Physics of Lipids. 2020 Oct 1; 232:104953.

47. Müller RH, Mäder K, Gohla S. Solid lipid nanoparticles (SLN) for controlled drug delivery-a review of the state of the art. European journal of pharmaceutics and biopharmaceutics. 2000 Jul 3; 50(1):161-77. 
48. Wissing SA, Kayser O, Müller RH. Solid lipid nanoparticles for parenteral drug delivery. Advanced drug delivery reviews. 2004 May 7; 56(9):1257-72.

49. Suvarna G, Narender D, Kishan V. Preparation, characterization and in vivo evaluation of rosuvastatin calcium loaded solid lipid nanoparticles. Int J Pharm Sci Nanotech. 2015; 9:2779-85.

50. Gorre TR, Swetha E and Narendar D. Role of isradipine loaded solid lipid nanoparticles in the pharmacodynamic effect of isradipine in rats. Drug research. 2017; 67(03):163-169.

51. Dudhipala, N.; Puchchakayala, G. Capecitabine lipid nanoparticles for anti-colon cancer activity in 1,2dimethylhydrazine-induced colon cancer: preparation, cytotoxic, pharmacokinetic, and pathological evaluation. Drug Development and Industrial Pharmacy 2018; 44:1572-1582.

52. Mehnert W, Mader K. Solid lipid nanoparticles: Production, characterization and applications. Advanced Drug Delivery Reviews. 2001; 47(2-3):165-96.

53. Uner M, Yener G. Importance of solid lipid nanoparticles (SLN) in various administration routes and future perspectives. International Journal of Nanomedicine. 2007; 2(3):289-300.

54. Akshaya Tatke, Narendar Dudhipala, Karthik Yadav Janga, Sai Prachetan Balguri, Bharathi Avula, Monica M. Jablonski Soumyajit Majumdar. In Situ Gel of Triamcinolone AcetonideLoaded Solid Lipid Nanoparticles for Improved Topical Ocular Delivery: Tear Kinetics and Ocular Disposition Studies. Nanomaterials (Basel). 2018; 9(1). pii: E33. doi: 10.3390/nano 9010033.

55. Youssef A, Dudhipala N, Majumdar S. Ciprofloxacin loaded nanostructured lipid carriers incorporated into in-situ gels to improve management of bacterial endophthalmitis. Pharmaceutics. 2020 Jun; 12(6):572.

56. Jenning V, Thünemann AF, Gohla SH. Characterisation of a novel solid lipid nanoparticle carrier system based on binary mixtures of liquid and solid lipids. International Journal of Pharmaceutics. 2000 Apr 20; 199(2):167-77.

57. Dingler A, R. P. Blum, H. Niehus, R. H. Muller, S. Gohla. Solid lipid nanoparticles (SLNTM/LipopearlsTM) a pharmaceutical and cosmetic carrier for teh application of vitamin $\mathrm{E}$ in dermal products. Journal of microencapsulation. 1999; 16 (6):751-767.

58. Dudhipala N, Youssef AA, Banala N. Colloidal lipid nanodispersion enriched hydrogel of antifungal agent for management of fungal infections: Comparative in-vitro, ex-vivo and in-vivo evaluation for oral and topical application. Chemistry and Physics of Lipids. 2020 Nov 1; 233:104981.

59. Weiss J, Decker EA, McClements DJ, Kristbergsson K, Helgason T, Awad T. Solid lipid nanoparticles as delivery systems for bioactive food components. Food Biophysics. 2008 Jun 1; 3(2):146-54.

60. Müller RH, Runge S, Ravelli V, Mehnert W, Thünemann AF, Souto EB. Oral bioavailability of cyclosporine: solid lipid nanoparticles (SLN $囚$ ) versus drug nanocrystals. International journal of pharmaceutics. 2006 Jul 6; 317(1):82-9.

61. Müller RH, Runge SA, Ravelli V, Thünemann AF, Mehnert W, Souto EB. Cyclosporine-loaded solid lipid nanoparticles (SLN $®$ ): Drug-lipid physicochemical interactions and characterization of drug incorporation. European journal of pharmaceutics and biopharmaceutics. 2008 Mar 1; 68(3):535-44.

62. Alex MA, Chacko AJ, Jose S, Souto EB. Lopinavir loaded solid lipid nanoparticles (SLN) for intestinal lymphatic targeting. European journal of pharmaceutical sciences. 2011 Jan 18; 42(1-2):11-8.

63. Dudhipala N, Veerabrahma K. Pharmacokinetic and pharmacodynamic studies of nisoldipine-loaded solid lipid nanoparticles developed by central composite design. Drug development and industrial pharmacy. 2015 Dec 2; 41(12):1968-77.

64. Nooli M, Chella N, Kulhari H, Shastri NR, Sistla R. Solid lipid nanoparticles as vesicles for oral delivery of olmesartan medoxomil: formulation, optimization and in vivo evaluation. Drug development and industrial pharmacy. 2017 Apr 3; 43(4):611-7.

65. Veerabrahma K. Development of olmesartan medoxomil lipidbased nanoparticles and nanosuspension: preparation, characterization and comparative pharmacokinetic evaluation. Artificial cells, nanomedicine, and biotechnology. 2018 Feb; 46(1):126.

66. Pandya NT, Jani P, Vanza J, Tandel H. Solid lipid nanoparticles as an efficient drug delivery system of olmesartan medoxomil for the treatment of hypertension. Colloids and Surfaces B: Biointerfaces. 2018 May 1; 165:37-44.

67. Dudhipala N, Veerabrahma K. Candesartan cilexetil loaded solid lipid nanoparticles for oral delivery: characterization, pharmacokinetic and pharmacodynamic evaluation. Drug delivery. 2016 Feb 12; 23(2):395-404.

68. Zhang Z, Gao F, Bu H, Xiao J, Li Y. Solid lipid nanoparticles loading candesartan cilexetil enhance oral bioavailability: in vitro characteristics and absorption mechanism in rats. Nanomedicine: Nanotechnology, Biology and Medicine. 2012 Jul 1; 8(5):740-7.

69. Gondrala UK, Dudhipala N, Kishan V. Preparation, characterization and in vivo evaluation of felodipine solid-lipid nanoparticles for improved oral bioavailability. Measurement. 2015; 10(10): 2995-3002.

70. Kishan V, Sandeep V, Narendar D, Arjun N. Lacidipine loaded solid lipid nanoparticles for oral delivery: preparation, characterization and in vivo evaluation. International Journal of Pharmaceutical Sciences and Nanotechnology. 2016; 9(6):352430.

71. Dudhipala N, Veerabrahma K. Improved anti-hyperlipidemic activity of Rosuvastatin Calcium via lipid nanoparticles: Pharmacokinetic and pharmacodynamic evaluation. European Journal of Pharmaceutics and Biopharmaceutics. 2017 Jan 1; 110:47-57.

72. Padhye SG, Nagarsenker MS. Simvastatin solid lipid nanoparticles for oral delivery: formulation development and in vivo evaluation. Indian journal of pharmaceutical sciences. 2013 Sep; 75(5):591.

73. Wang $H$, Wang $H$, Yang W, Yu M, Sun S, Xie B. Improved oral bioavailability and liver targeting of sorafenib solid lipid nanoparticles in rats. AAPS PharmSciTech. 2018 Feb 1; 19(2):761-8.

74. Dudhipala N, Janga KY. Lipid nanoparticles of zaleplon for improved oral delivery by Box-Behnken design: optimization, in vitro and in vivo evaluation. Drug development and industrial pharmacy. 2017 Jul 3; 43(7):1205-14.

75. Gidwani B, Vyas A. Preparation, characterization, and optimization of altretamine-loaded solid lipid nanoparticles using Box-Behnken design and response surface methodology. Artificial cells, nanomedicine, and biotechnology. 2016 Feb 17; 44(2):571-80.

76. Burra M, Jukanti R, Janga KY, Sunkavalli S, Velpula A, Ampati S, Jayaveera KN. Enhanced intestinal absorption and bioavailability of raloxifene hydrochloride via lyophilized solid lipid nanoparticles. Advanced Powder Technology. 2013 Jan 1; 24(1):393-402. 